\title{
The Liquid and Plastic Limit Data Treated System Based on VC++
}

\author{
Xiaodong Zhang, Jianqiao Li, Ruiyang Shi, Meng Zou, Yang Wang, Hao Li \\ Key laboratory of Bionic Engineering (Ministry of Education, China \\ Jilin University \\ Changchun, P. R. China \\ e-mail: xiaodong10@mails.jlu.edu.cn; jqli@jlu.edu.cn; shiry11@mails.jlu.edu.cn; zoumeng@jlu.edu.cn; \\ wangyang0718@mails.jlu.edu.cn; lihao1987102@sina.com
}

\begin{abstract}
According to two standards for soil test methods with liquid and plastic limit combined test, a liquid and plastic limit data treated system was developed using object-oriented visual programming Microsoft Visual $\mathrm{C}++6.0$ based on analytical method. The flow char indicated that programs of the system used select structure and its nested structure as main its algorithm. Contrasted with manual graphic method, the liquid and plastic limit data treated system had high efficiency and reliable accuracy.
\end{abstract}

Keywords-object-oriented visual programming; $V C++$; soil science; analytical method; liquid limit, plastic limit

\section{INTRODUCTION}

The soil liquid limit $w_{\mathrm{L}}$ (shorted as $w_{\mathrm{L}}$ ) and soil plastic limit $w_{\mathrm{P}}$ (shorted as $w_{\mathrm{P}}$ ) are both fundamental physical standards for evaluating mechanical properties of soil [1-3], which are often collectively referred to as the "Atterberg Limits ". Traditionally, using manual graphic method to treat the data of $w_{\mathrm{L}}$ and $w_{\mathrm{P}}$ had a low efficiency and caused man-made error easily. With the aids of computer hardware and software technology, data treated software or object-oriented visual program software were gradually applied to analyzing $w_{\mathrm{L}}$ and $w_{\mathrm{P}}$ data, which heighten the efficiency and improve accuracy during data treated process. However, there is almost not an object-oriented visual program for treating $w_{\mathrm{L}}$ and $w_{\mathrm{P}}$ data based on analytic method at present.

In this paper, according to two standard for soil test methods about liquid and plastic limit combined test, the object-oriented visual programming tool Microsoft Visual $\mathrm{C}++6.0$ was used to develop an liquid and plastic limit data treated system referring to analytic method, the main algorithm of which is choose structure and its nested structure. Experimental results indicated that this system had a high efficiency and reliable accuracy compared with manual graphic method to treat $w_{\mathrm{L}}$ and $w_{\mathrm{P}}$ data.

\section{RADICAL PRINCIPLE}

The radical principle of liquid and plastic limit combined test for treating $w_{\mathrm{L}}$ and $w_{\mathrm{P}}$ data referr to $G B / T$ 50123-1999 Standard for Soil Test Method (shorted as Standard) [4] and JTG E40-2007 Test Methods of Soils for Highway Engineering (shorted as Test Methods) [5]. In this paper, Standard was used as an example to discuss the data treated process with analytical method. In Standard, the equipment for liquid and plastic limit combined test was GYS-2 photoelectric liquid-plastic tester (Nan Jing soil instrument factory) with $76 \mathrm{~g}$ and $30^{\circ}$ cone penetrator.

(1) Three points (A point, $\mathrm{B}$ point and $\mathrm{C}$ point) corresponding to three different water contents of a soil specimen were chosen for liquid and plastic limit combined test. The depth of cone penetrator for each point were $3 \sim 4 \mathrm{~mm}$ (A point), 5 7mm (B point) and $15 \sim 17 \mathrm{~mm}$ (C point).

(2) The coordinate for each point was supposed to $\mathrm{A}\left(w_{\mathrm{A}}\right.$, $\left.h_{\mathrm{A}}\right), \mathrm{B}\left(w_{\mathrm{B}}, h_{\mathrm{B}}\right), \mathrm{C}\left(w_{\mathrm{C}}, h_{\mathrm{C}}\right)$. So straight line $\mathrm{AC}$ and straight line $\mathrm{BC}$ are expressed respectively as: Straight line AC:

$$
\frac{\lg w_{\mathrm{C}}-\lg w_{\mathrm{A}}}{\lg h_{\mathrm{C}}-\lg h_{\mathrm{A}}}=\frac{\lg w_{\mathrm{C}}-\lg w_{\mathrm{M}}}{\mathrm{g} h_{\mathrm{C}}-\lg h_{\mathrm{P}}}
$$

Straight line BC:

$$
\frac{\lg w_{\mathrm{C}}-\lg w_{\mathrm{B}}}{\lg h_{\mathrm{C}}-\lg h_{\mathrm{B}}}=\frac{\lg w_{\mathrm{C}}-\lg w_{\mathrm{N}}}{\operatorname{g} h_{\mathrm{C}}-\lg h_{\mathrm{P}}}
$$

where $w_{\mathrm{A}}, w_{\mathrm{B}}$ and $w_{\mathrm{C}}$ were the water contents of three different water contents for a soil specimen corresponding to each point respectively. $h_{\mathrm{A}}, h_{\mathrm{B}}$ and $h_{\mathrm{C}}$ were the depths of cone penetrator corresponding to each point respectively. The depth of cone penetrator $h_{\mathrm{P}}$ equaled $2 \mathrm{~mm}$. So the values of $w_{\mathrm{M}}$ and $w_{\mathrm{N}}$ could be calculated according to Equ. (1) and Equ. (2).

(3) If the absolute value of difference between $w_{M}$ and $w_{N}$ was less than $2, h_{\mathrm{P}}$ and the average value $\bar{w}$ between $w_{\mathrm{M}}$ and $w_{\mathrm{N}}$ were used as the coordinate of point $\mathrm{D}(\bar{w}$, $h_{\mathrm{P}}$ ) and straight line CD was drawn (Fig. 1). The equation of straight line $\mathrm{CD}$ was described as:

$$
\lg w=\frac{\lg \left(w_{\mathrm{C}} / \bar{w}\right) \lg \left(h / h_{\mathrm{C}}\right)}{\lg \left(h_{\mathrm{C}} / h_{\mathrm{P}}\right)}+\lg w_{\mathrm{C}}
$$

where $w$ and $h$ were variable.

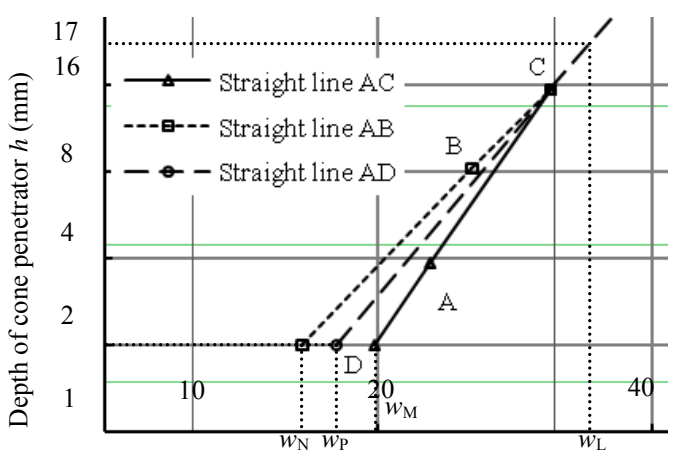

Figure 1. The relation between the depht of cone penetrator and the water content of soil. 


\section{PROGRAM DESIGN}

\section{A. Program flow chart}

The flow chart of the liquid and plastic limit data treated system was illustrated in Fig.2. In flow chart, Equ.(6) and Equ.(7) were expressed respectively as:

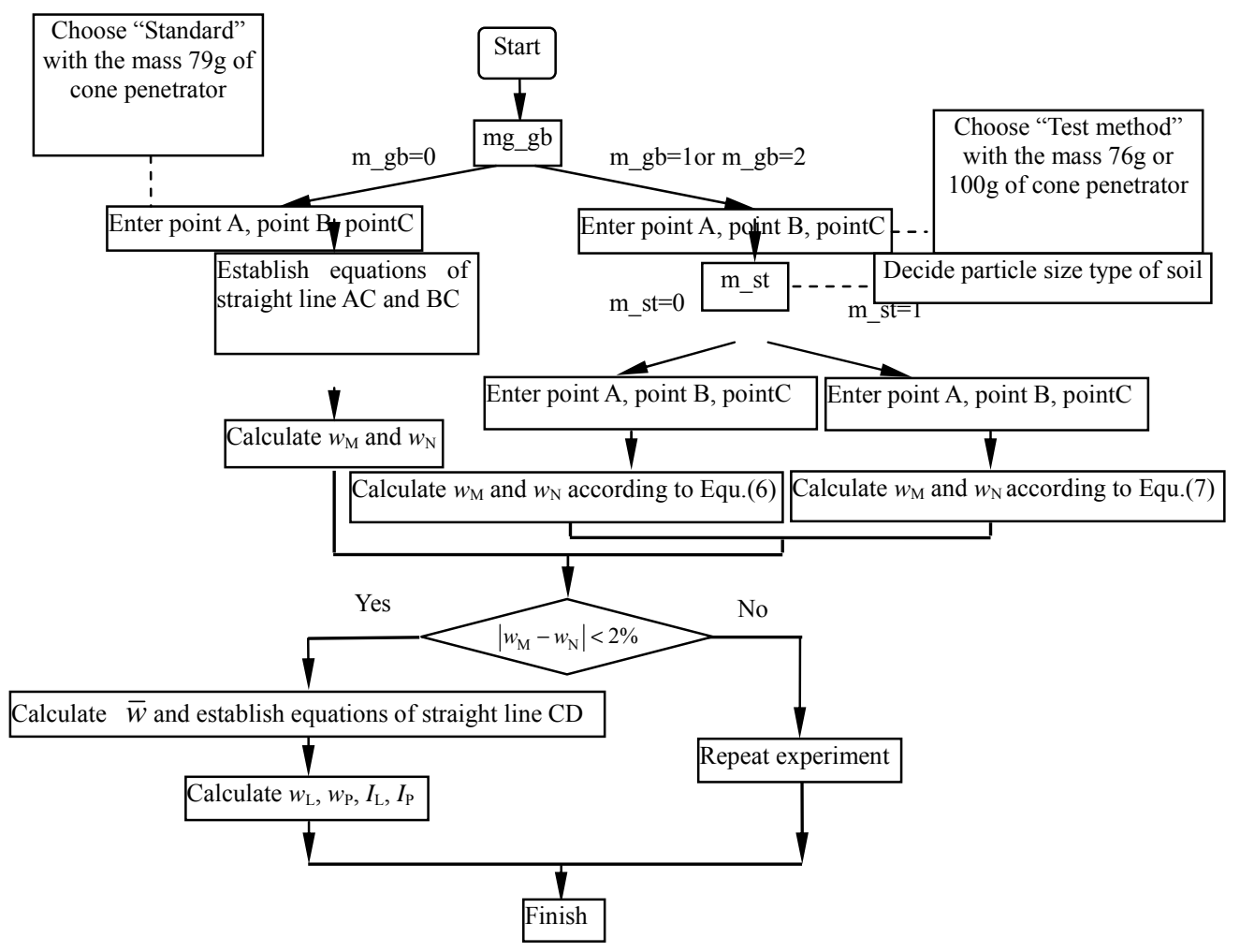

Figure 2. The flow chart of program

$$
\begin{gathered}
h_{\mathrm{p}}=29.6-1.22 w_{\mathrm{L}}+0.017 w_{\mathrm{L}}^{2}-0.000074 w_{\mathrm{L}}^{3} \\
h_{\mathrm{p}}=\frac{w_{\mathrm{L}}}{0.524 w_{\mathrm{L}}-7.606}
\end{gathered}
$$

Flow chart indicated that select structure and its nested structure as the main algorithm of the liquid and plastic limit data treated system. So switch statement and condition statement were chosen to compose process program of the system.

\section{B. Dialog box}

The liquid and plastic limit data treated system was developed under Microsoft Visual C++6.0[7-8]. The dialog box of the system was established from MFC AppWizard based on MFC, the caption of which was "Liquid Limit and Plastic Limit Data Treating System" (Fig.3). Table. I showed main controls distributed on the dialog box.

\section{TABLE I. CONTROLS ON THE DIALOG BOX}

\begin{tabular}{|c|c|}
\hline Main controls & Function \\
\hline Edit Box & Enter data or export result \\
\hline Button & Execute program \\
\hline Radio Button & $\begin{array}{c}\text { Chose "Standard " or " Test } \\
\text { Methods " and soil type }\end{array}$ \\
\hline Static & Show controls function \\
\hline Group Box & Divide different part of dialog box \\
\hline
\end{tabular}

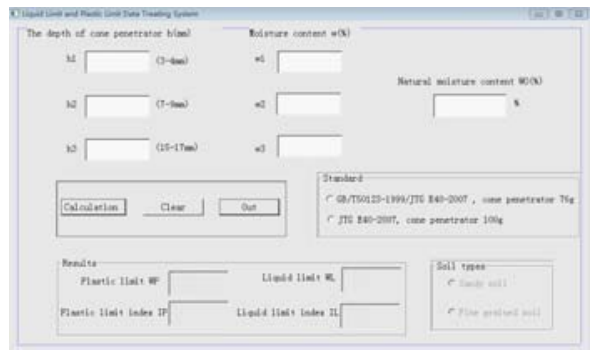

Figure 3. Dialog box

\section{Program exemplification}

In "Member Variables" label at "Class wizard", edit box and member variables were linked and member variables were set as "Double" type. Clicking the "Group" in "General" label of "GB/T50123-1999, cone penetrator 76g" and "Sandy soil" radio button attributes, the radio buttons were separated into "Standard" group and "Soil type" group. In "Member Variables" label at "Class wizard", the edit box and member variables were linked and member variables were set as "Double" type. "GB/T50123-1999, cone penetrator $76 \mathrm{~g}$ " radio button and "Sandy soil" radio button were related with member variables and member variables 
were set as "Int" type in order to when "Calculation" button was clicked, only one data treated process was executed, which could prevent conflicts among programs.

In "Message Maps" label at "ClassWizard", response function was added to "Calculation" button. Firstly, "Calculation" button ID was selected from "Object ID" list box, and BN_CLICKED message was selected from "Message" list box. Then the response function name was defined as "OnJs" trough clicking "Add Function" button. After clicking "Edit Code" button, response function was added in "CMyDlg" class. Before the data treated program was executed, selecting "standard" and "soil type" and then clicking "Calculation" button, the response function called the data treated program in "OnJs" to treat data which were gained from liquid and plastic limit combined test.

Because Test Methods has similar data treated process to standard as a whole (Fig.2), in this paper, the data treated program of "GB/T50123-1999, cone penetrator $76 \mathrm{~g}$ " was expressed as void CMyDlg::OnJs() \{

double $k_{\mathrm{AC}}, k_{\mathrm{BC}}, b_{\mathrm{AC}}, b_{\mathrm{BC}}, w_{\mathrm{M}}, w_{\mathrm{N}}, \bar{w}, \bar{b}, \bar{k}=0.0$;

UpdateData();

$k_{\mathrm{AC}}=\left(\log 10\left(h_{\mathrm{C}}\right)-\log 10\left(h_{\mathrm{A}}\right)\right) /\left(\log 10\left(w_{\mathrm{C}}\right)-\log 10\left(w_{\mathrm{A}}\right)\right) ; / /$ The slope of straight line AC

$k_{\mathrm{BC}}=\left(\log 10\left(h_{\mathrm{C}}\right)-\log 10\left(h_{\mathrm{B}}\right)\right) /\left(\log 10\left(w_{\mathrm{C}}\right)-\log 10\left(w_{\mathrm{B}}\right)\right) ; / / \mathrm{The}$ slope of straight line $\mathrm{BC}$

$b_{\mathrm{AC}}=\log 10\left(h_{\mathrm{C}}\right)-k_{\mathrm{AC}} * \log 10\left(w_{\mathrm{C}}\right) ; / /$ The intercept of straight line $\mathrm{AC}$ line $\mathrm{BC}$

$b_{\mathrm{BC}}=\log 10\left(h_{\mathrm{C}}\right)-k_{\mathrm{BC}} * \log 10\left(w_{\mathrm{C}}\right) ; / /$ The intercept of straight $w_{\mathrm{M}}=\operatorname{pow}\left(10,\left(\log 10(2)-b_{\mathrm{AC}}\right) / k_{\mathrm{AC}}\right) ; / /$ The water content of the depth of cone penetrator $2 \mathrm{~mm}$ from straight line $\mathrm{AC}$

$w_{\mathrm{N}}=\operatorname{pow}\left(10,\left(\log 10(2)-b_{\mathrm{BC}}\right) / k_{\mathrm{BC}}\right) ; / /$ The

water content of the depth of cone penetrator

$2 \mathrm{~mm}$ from straight line BC switch(m_gb)

\{

UpdateData();

case -1 :

MessageBox("Please select standard! ");

break;

case 0 :

UpdateData();

if $\left(\operatorname{fabs}\left(w_{M}-w_{N}\right)>=2 \%\right)$

\{

MessageBox("Please repeat experiment! ");

\}

else

\{

MessageBox("GB/T50123-1999, cone penetrator 76g!"); $\bar{w}=\left(w_{\mathrm{M}}+w_{\mathrm{N}}\right) / 2$;

$\bar{k}=\left(\log 10\left(h_{\mathrm{C}}\right)-\log 10(2)\right) /\left(\log 10\left(w_{\mathrm{C}}\right)-\log 10(\bar{w})\right) ; / /$ The slope of straight line CD $\bar{b}=\log 10\left(h_{\mathrm{C}}\right)-\mathrm{kav}^{*} \log 10\left(w_{\mathrm{C}}\right) ; / /$ The intercept of straight line $\mathrm{CD}$

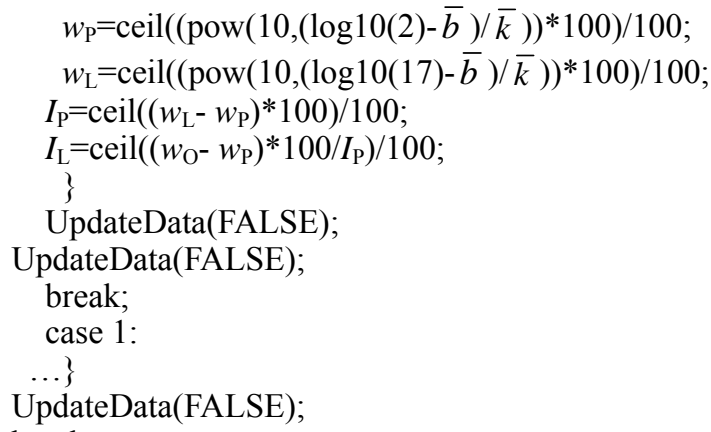

\section{EXAMPLE ANALYSIS}

Three soil mixed specimens were gained from lakeside (A), forest (B) and paddy field (C) with fold sampling method. Particle size distribution experiments showed that all three soil specimens were all sandy soil [9-11].

GYS-2 photoelectric liquid-plastic tester with $76 \mathrm{~g}$ and $30^{\circ}$ cone penetrator was used for liquid and plastic limit combined test. The test data were treated with three methods: Liquid Limit and Plastic Limit Data Treated System, Microsoft Office Excel 2007 and manual graphic method. The data treated results were showed in Table. II

Table. II showed that there were the same results between the system and Microsoft Office Excel 2007, which illustrated that liquid and plastic limit data treated system had a reliable accuracy. Compared with manual graphic method, the system took average 6.5 times shorter than manual graphic method, so the system could improve the efficiency to treating data .

\section{CONCLUSIONS}

A liquid and plastic limit data treated system was developed under Microsoft Visual $\mathrm{C}++6.0$ with analytical method based on two standards for soil test methods. The flow chart showed that select structure and its nested structure were main algorithms of the system. Compared with manual graphic method, the system had reliable accuracy and high efficiency

\section{ACKNOWLEDGMENT}

This research was supported by the National Natural Science Foundation (Grant No.50875107) and the National Hi-Tech Program of China (Grant No. 2010AA101401-3).

TABLE II. THE DATA TREATED RESULTS

\begin{tabular}{|c|c|c|c|c|c|c|}
\hline \multirow{2}{*}{ Specimen } & \multicolumn{2}{|c|}{$\begin{array}{c}\text { Soil Liquid Limit and Plastic } \\
\text { Limit Data Treating System }\end{array}$} & \multicolumn{2}{|c|}{ Microsoft Office Excel 2007} & \multicolumn{3}{c|}{ Manual graphic method } \\
\cline { 2 - 7 } & Liquid limit & Plastic limit & Liquid limit & Plastic limit & Liquid limit & Plastic limit \\
\hline
\end{tabular}




\begin{tabular}{|c|c|c|c|c|c|c|}
\hline & $w_{\mathrm{L}} / \%$ & $w_{\mathrm{P}} / \%$ & $w_{\mathrm{L}} / \%$ & $w_{\mathrm{P}} / \%$ & $w_{\mathrm{L}} / \%$ & $w_{\mathrm{P}} / \%$ \\
\hline $\mathrm{A}$ & 79.1 & 50.9 & 79.1 & 50.9 & 79.2 & 47.6 \\
\hline $\mathrm{B}$ & 56.5 & 39.9 & 56.5 & 39.9 & 56.5 & 42.6 \\
\hline $\mathrm{C}$ & 31.6 & 20.2 & 31.6 & 20.2 & 33.4 & 21.2 \\
\hline
\end{tabular}

\section{REFERENCES}

[1] B. Dolinar, M. Mišič and L. Trauner, "Correlation between surface area and atterberg limits of fine-grained soils," Clays and Clay Minerals, vol. 55, Oct. 2012, pp. 519-523, doi: $10.1346 / \mathrm{ccmn}$. 2007.0550506.

[2] R. Zentar, N.-E. Abriak, V. Dubois, "Effects of salts and organic matter on Atterberg limits of dredged marine sediments," Applied Clay Science, vol 42, April 2008, pp. 391-397, doi: 10.1016/j.clay.2008.04.003.

[3] A. Sridharan, H. B. Nagaraj, "Plastic limit and compaction characteristics of fine-grained soils," Ground Improvement, vol 9, Jan. 2005, pp.17-22, doi: 10.1680/grim.2005.9.1.17.

[4] GB/T 50123-1999, "Standard for soil test method," 1999.

[5] JTG E40-2007, "Test methods of soils for highway engineering," 2007.

[6] J.Q.Li, X. D. Zhang, M. Zou, H. Li, "Soil liquid limit and plastic limit treating system based on analytic method, " Procedia Earth and Planetary Science, vol. 5, pp. 175-179, doi: 10.1016/j.proeps.2012.01.031.

[7] D. J. Kruglinski, S. Wingo, G. W. Sheperd, Programming Microsoft Visual C++, 5th ed., vol. 2. Washington: Microsoft Press, 1998, pp, 103-134, 367-411.

[8] V. Rajaraman, Computer programming in C, New Delhi: Prentice-Hall of India Private Limited, 1994, pp.6-21, 38-46, 72-85.

[9] H. Rahardjo, A. Satyanaga, E.-C. Leong, Y. S. Ng, H. T. C. Pang, "Variability of residual soil properties," Engineering Geology, vol. 141-142, July 2012, pp. 124-140, doi: 10.1016/ j.enggeo. 2012.05.009.

[10] ASTM D422-1963, "Standard Test Method for Particle-Size Analysis of Soils, " 2007.

[11] ASTM D6913-04, "Standard Test Methods for Particle-Size Distribution (Gradation) of Soils Using Sieve Analysis,” 2009. 